\title{
The change of land use and land suitability of agriculture due to flow liquefaction in Palu and Sigi valley after the Palu earthquake in September 2018
}

\author{
Sukiman Nurdin $^{1 *}$, Amar Akbar Ali², F.A Marhum ${ }^{3}$, Sriyati Ramadhani ${ }^{1}$ \\ ${ }^{1}$ Civil Engineering, Tadulako University, Palu, Central Sulawesi 94118, Indonesia \\ ${ }^{2}$ Architectural Engineering Tadulako University, Palu, Central Sulawesi 94118, Indonesia \\ ${ }^{3}$ Geologycal Engineering Tadulako University, Palu, Central Sulawesi 94118, Indonesia
}

\begin{abstract}
After the Palu earthquake in 2018, there were many paddy fields has been impacted by liquefaction in three locations, namely, Sibalaya is around $30 \mathrm{Ha}$, Jono Oge is about 1784 ha, and Petobo was affected around $388 \mathrm{Ha}$. The entire paddy fields affected are about $2.202 \mathrm{Ha}$. The procedure model was used to analyse the most suitable location for the rainfed agricultural and irrigated crops after the Palu Earthquake in September 2018. Four levels of land suitability class were pre-pared based on five criteria: rainfall, temperature, slope percentage, soil types, and the spatial distribution of groundwater wells. The process in land suitability analysis with GIS after the suitability class of each parameter is an overlay process after some exploration and testing with the Land; the results show about $65 \%$ of the paddy fields land is in category S2; this limiting factor will affect its productivity, requiring additional inputs. The land users themselves can usually overcome these boundaries. And others about in class S3 is about $35 \%$ Paddy fields Land has a heavy limiting factor, which will significantly affect its productivity, requiring more additional input than Land Classified as S2. To overcome the limiting factor in S3 requires high capital, so there needs to be assistance or intervention (intervention) from the government or the private sector.
\end{abstract}

\section{Introduction}

\subsection{Background}

Indonesia lies in a tectonically active region and is exposed to a range of related natural hazards. On 28 September 2018, a 7.4 magnitudes earthquake occurred in Central Sulawesi province, causing landslides, major liquefaction events and a near-field tsunami, which struck the coast of Palu City and Donggla District. According to the National Disaster Management Agency (BNPB) the death toll is 2,256, while the number of missing persons total 1,309, and over 220 thousand people have been displaced[1][2][3].

The disaster has caused extensive damage to human settlements and buildings (houses, government offices, schools, hospitals and health centres) and infrastructure (roads, water supply, sanitation and irrigation facilities). The extent of the damage is estimated as follows[4][5][6]. Approximately 69,000 houses have been damaged, of, which 3,800 houses were damaged by liquefaction; 1,509 schools have been damaged and (temporarily) closed; 67 health centers and 17 hospitals suffered damages, limiting (or preventing entirely) their ability to provide health services; Some $42 \mathrm{~km}$ of raw water transmission and $100 \mathrm{~km}$ of water supply systems were damaged, causing people to rely on groundwater resources;Some $95 \mathrm{~km}$ of the canals in the Gumbasa irrigation system have been damaged, and the entire
8,180 command area is (for now) not being irrigated; and some $16 \mathrm{~km}$ of river works and about $20 \mathrm{~km}$ of coastal protection works have been damaged, exposing some 30,000 households to flooding risks.

The horizontal movement (strike-slip) had occurred along the Palu Koro geological fault and estimated (based on satellite imagery) that the Earthquake had caused 4-6m of horizontal movement at the surface of the fault line[[7][8][9].

On 28 April 2019, the Gumbasa area suffered from flooding of the Bangga River. There were no casualties, but the Bangga township was flooded by $1 \frac{1}{2}-3$ meters of water that left houses covered in $1-2 \mathrm{~m}$ of sand and destroyed local tree plantations (mainly cocoa was affected). Other villages were also affected by floods on 28 April 2019, although not as severe as at Bangga. In June 2019, the construction of a large dike started to contain the Bangga River and prevent future catastrophic floods[10][11].

Land suitability evaluation for agricultural land-use planning has five physical control factors: rainfall, temperature, slope percentage, soil types, and the distribution of groundwater wells, which are used to decide the best agricultural land use for a particular area, for both rainfed agricultural and irrigated crops. Weighted Overlay tools were used to locate the most suitable site for rainfed agricultural and irrigated crops. Inland suitability, modelling all the five factors are Weighted based on their level of influence using multi-

Corresponding author: s.nurdin@gmail.com 
criteria evaluation to generate a land suitability map. Mapping agricultural land is thus vital to locate and rank which areas are highly suitable and less suitable.

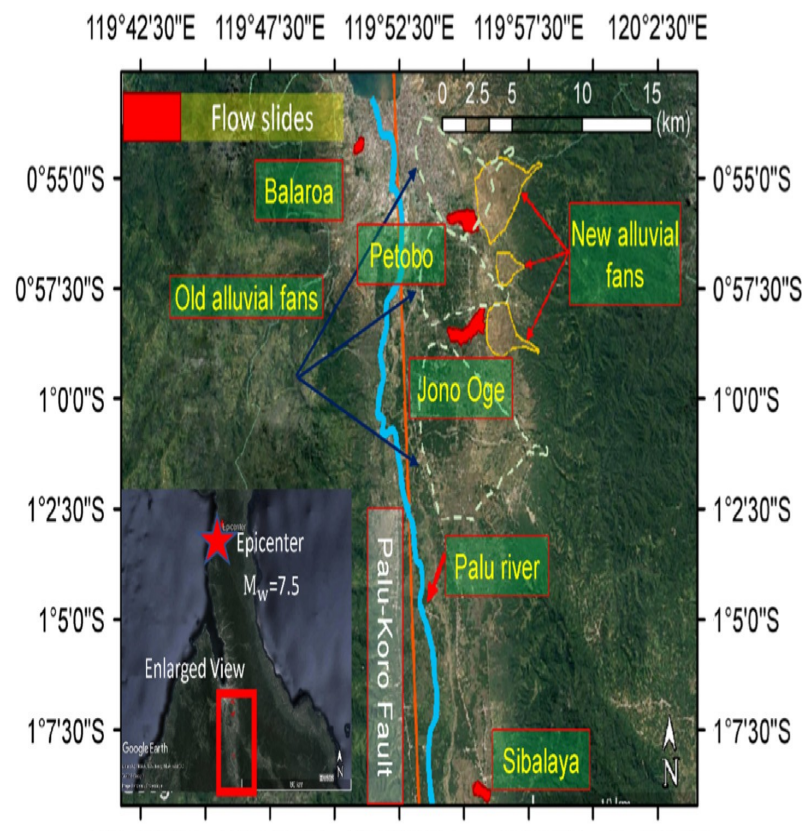

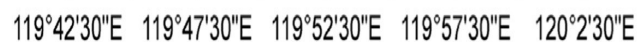

Fig. 1. Locations of liquefaction cross the paddy field along the main canal of Gumbasa Irrigation

Source: modified from [9].

\subsection{Location of study}

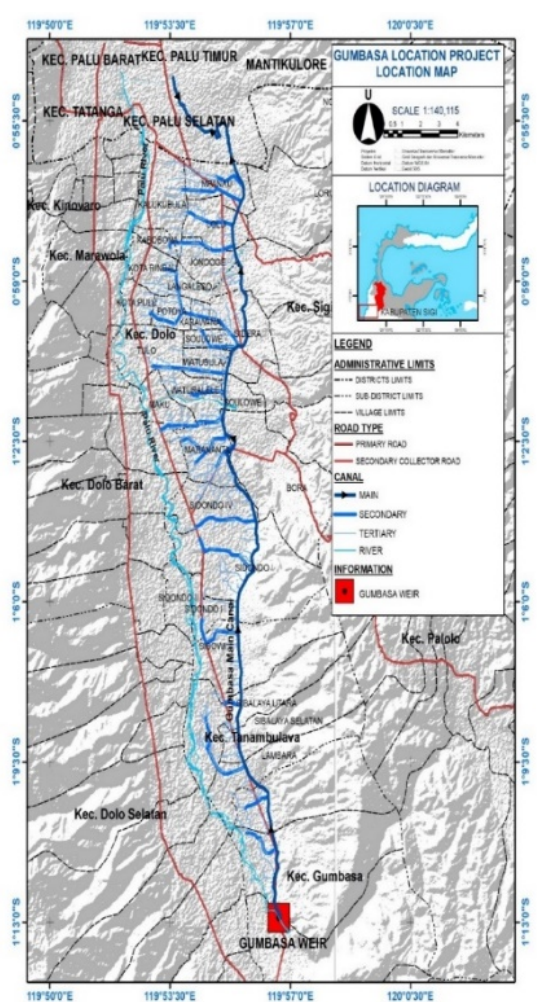

Fig. 2. Location of the Gumbasa irrigation area.

The Gumbasa irrigation system is situated on the right bank of the Palu River between 1 and $40 \mathrm{~km}$ South of Palu city in Palu City and Sigi District in Central Sulawesi Province (see Figure 2). The Gumbasa
Irrigation System belongs to the Palu river basin managed under the BWSS III, containing the Palu Lariang, Parigi Poso and Kalukku Karamariver basins. The Gumbasa irrigation system is more extensive than $3,000 \mathrm{Ha}$ and is classified as a central government scheme.

\subsection{Purpose of land use and land suitability assessment}

The main target of this paper is to locate the optimum Land suitable for agriculture, both rainfed and irrigated, while the second goal is to present the classification and change detection of land use after the Palu Earthquake in September 2018 Palu and Sigi Valley.

\section{Methods of land suitability assessment}

The procedure model was used to analyze the most suitable location for the rainfed agricultural and irrigated crops after the Palu Earthquake in September 2018. There are four levels of land suitability class as shown in. The suitability was prepared based on five criteria: rainfall, temperature, slope percentage, soil types, and the spatial distribution of groundwater wells. The process in land suitability analysis with GIS after the suitability class of each parameter is an overlay process. or overlap between parameters. This process is carried out to combine all the information from the parameters used in the suitability analysis

\subsection{Preparation stage}

Soil maps, legends and soil characteristics are land/soil resource data needed in assessing land suitability for strategic agricultural commodities. The data is collected in a database system and integrated with other data such as climate and slope details.

The stages of compiling land suitability maps for strategic agricultural commodities on a scale of 1:50,000 include:

1. Preparing a land map: Prepare a 1:50,000 scale soil map, especially in shapefile (.shp) format and the map legend, and a dataset of soil characteristics used for land suitability assessment of strategic agricultural commodities.

2. Checking topology, polygons, land characteristics: At this stage, a re-check is carried out on the soil map unit and the soil/land characteristics dataset, which will be used to assess land suitability for strategic agricultural commodities. Format and topology checks are carried out on each District/City level land map, as follows: First, the spatial and topological data formats need to be improved (especially polygon slivers and double lines/overlaying vertices). Second, clarify the number of Satuan Peta Tanah (SPT; soil mapping unit) with its legend.

3. Verifying land characteristics dataset: Verifying the completeness of land characteristics data is carried out on each SPT. The result of the activities 
at this stage is a semi-detailed soil map with a scale of 1:50,000 with a complete dataset of land characteristics. This data will be used for the land suitability assessment process for strategic agricultural commodities.

4. Preparing the land suitability map format and layout (template): The design and layout of the 1:50,000 scale land suitability map using the Indonesian topographical base map (RBI) at a scale of 1:50,000 and a scale of 1:25,000 published by the Geospatial Information Agency (BIG). The RBI map is a national map standard that all ministries and institutions must refer to to support the one map policy. District/city and sub-district boundaries follow the division of administrative areas following the directions of the Sigi District spatial plan for 2020-2040

\subsection{Stage of assessment and presentation of land suitability results}

The stage of assessment and presentation of land suitability results is based on existing data such as data on temperature, rainfall, soil texture, and slope. These data will then be overlaid/superimposed to produce land suitability data for agriculture in strategic areas.

Land suitability assessment activities are carried out on strategic agricultural commodities: rice, corn, soy beans, shallots, red chillies, oil palm, cocoa, sugar cane, and forage fodder.

This land suitability assessment is carried out with a matching system. This means that land qualities/land characteristics are matched with land use requirements, including plant growth requirements, environment and management, using the Land Suitability Assessment System (SPKL) program package version-2[12]

Reference is made to the Land Suitability Criteria for Agricultural Commodities [12] with several modifications and improvements to the 2016 FGD results. Land suitability is evaluated on the current land use (existing land use), an assessment before land management actions are carried out. This land suitability class describes the actual land potential, utilization constraints and required improvements. The results of the SPKL assessment produce tabular data on the land suitability class of each commodity based on the land map unit. The land suitability class is symbolized by $\mathrm{S} 1$, $\mathrm{S} 2, \mathrm{~S} 3$, and $\mathrm{N}$ to indicate the level of suitability.

To present land suitability assessment results, a table of actual land suitability classes (single crop) for strategic agricultural commodities is combined with SPT using GIS (Geographic Information System) so that land suitability maps of strategic farm commodities are arranged. The map is then ready for field verification [13].

\subsection{Field verification stage}

Field verification aims to check the results of the land suitability assessment with the performance of the strategic agricultural commodities being assessed. Validation is carried out mainly in strategic farm commodities' potential areas or production centers. For example, suppose the land suitability assessment results are not following the reality of plant growth in the field.
In that case, it is necessary to investigate[14]: 1) land suitability parameters and criteria, 2) land characteristics, 3) land management techniques and 4) plant growth and production.

\subsection{Land suitability map preparation stage}

After field verification, the land suitability map is corrected using the data from the field verification, and then a suitability map for strategic agricultural commodities is drawn up. Furthermore, it is laid out in an atlas format that refers to the standard form set by the BIG by including essential map components derived from the Indonesian Topographic Map (RBI), Digital Elevation Model (DEM), and administrative boundary maps. Each map uses district/city administrative boundaries. The map legend is compiled by presenting the land suitability class. Colours and codes symbolise class distinctions. A description of each colour and symbol is displayed in the form of a map legend.

\subsection{Data and information management and update stage}

The land suitability map that has been prepared and the database built is continuously updated with data and information on land resources based on data and land suitability criteria by the development of science and technology (varieties, cultivation technology and land management). The existing maps and data are actual and up-to-date sources of information to support food selfsufficiency efforts and the development of agricultural areas. With the development of science and technology, land suitability maps need to be updated, including data input regularly as required.

\section{Land suitability criteria and weighting}

\subsection{Land suitability concept}

Land suitability is the degree of suitability of a plot of land for a particular use. The suitability of the land can be assessed for its current condition (actual land suitability) or after improvements have been made (potential land suitability). Actual land suitability is land suitability based on data on biophysical properties of soil or land resources before the land is given the necessary inputs to overcome obstacles. The biophysical data is in soil and climatic characteristics related to the requirements for plant growth being evaluated. Potential land suitability describes the land suitability achieved if improvement efforts are made. The land being assessed in that case can be in the form of conversion forest, abandoned or unproductive land [15]. 


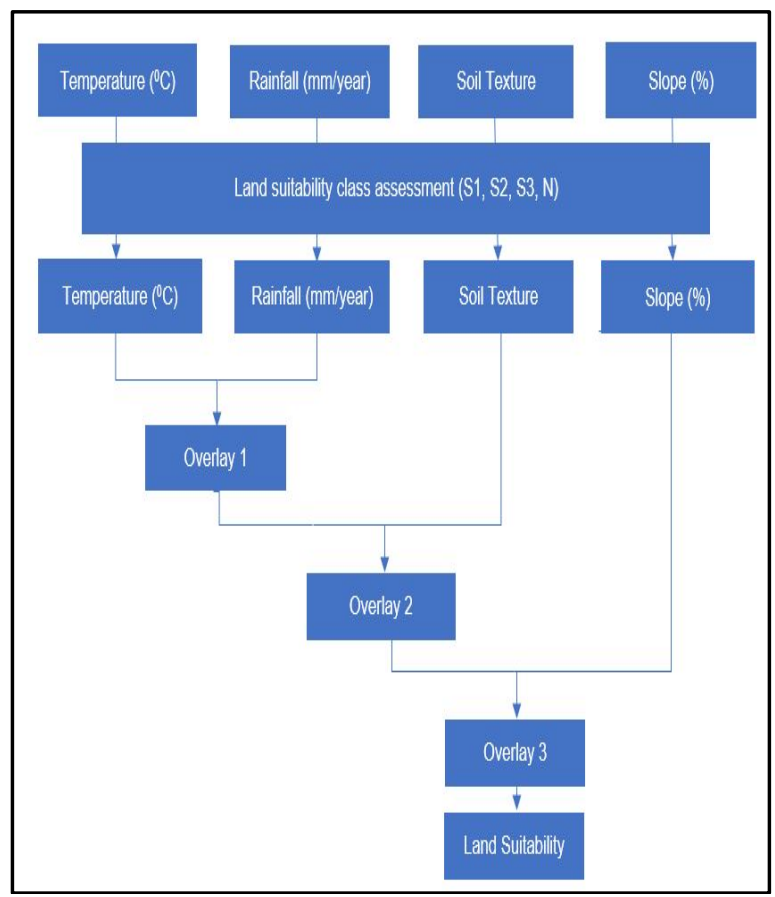

Fig. 3. Flowchart of land suitability analysis based on guidelines for the assessment of land suitability for strategic agricultural commodities, semi-detailed level 1:50,000 scale [12].

Land suitability classes can be divided into categories of land suitability based on the quality and characteristics of the land. Knowing the limiting factors will facilitate detailed interpretation in land use planning.

- Class S1, very suitable: The land has no significant limiting factor for sustainable use or only a minor limiting factor that will not reduce land productivity significantly.

- Class S2, moderately suitable: The land has a limiting factor, which will affect its productivity, requiring additional input. The farmers themselves can usually overcome these barriers.

- Class S3, marginally suitable: The land has a severely limiting factor, and this limiting factor will affect its productivity, requiring additional inputs that are more than land classified as S2. To overcome the limiting factor in S3 requires high capital, so there is a need for assistance or intervention by the Government or the private sector. Without this assistance, farmers will not be able to cope.

- Class N, not suitable: Land that is not suitable because it has a weighty limiting factor and factors that are difficult to overcome.
Table 1. Table of criteria and weighting of land suitability for irrigated rice [12].

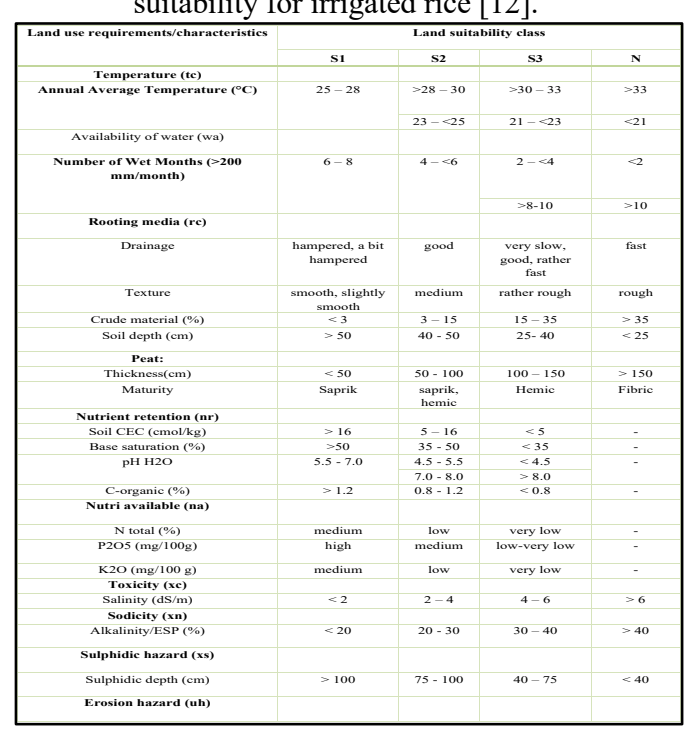

\subsection{Rainfall data}

Rainfall data is based on Bora Station data contained in the ESP Gumbasa Hydrology Report. In the Gumbasa irrigation area, there is only one station. Based on this data, the rainfall data in the Gumbasa irrigation area is classified from 2002 to 2019 . For more details, see the following table.

Tabel 2. Gumbasa Irrigation Area rainfall data table in 20022019.

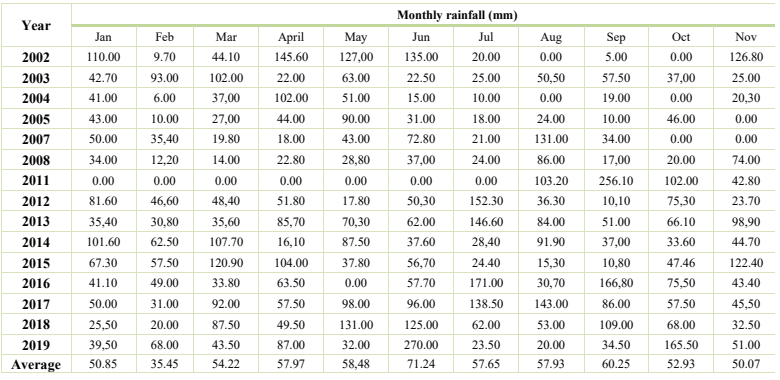

Source: Bora Station Based on Analysis Results of Hydrologists, 2021.

\subsection{Temperature data}

The temperature conditions in the Gumbasa irrigation area are very diverse, and this is based on data from the BMKG (Meteorology, Climatology and Geophysics Agency) with the Bora Station branch issuing temperature data from 2002 to 2019 in the Gumbasa irrigation area located in 7 sub-districts located in Sigi District and Palu City. Temperature conditions are critical in the land suitability assessment process because this is a significant factor in assessing the land potential and advantages in strategic agricultural development. 
Table 3. Table of temperature data for Gumbasa Irrigation Area in $2002-2019$.

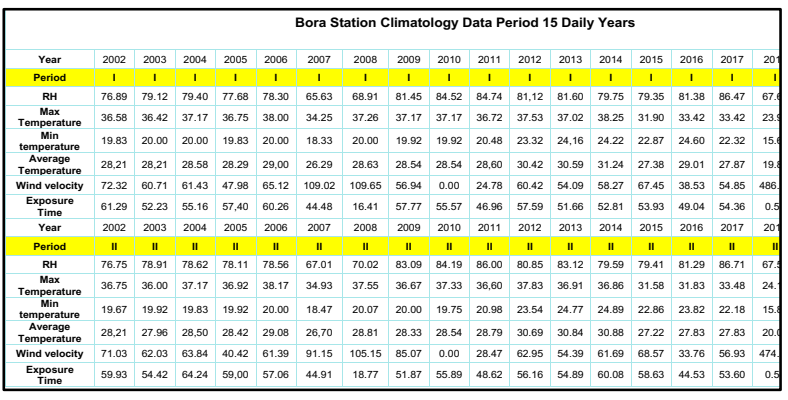

\subsection{Soil type data}

Concerning soil mapping units (SPT) on the format and topology found in the Gumbasa irrigation area, there are 14 types of SPT. This is based on data published by the Center for Agricultural Land Resources (BBSDLP) in 2016, specifically for Sigi District and Palu City. The soil mapping unit is very influential in developing agriculture in the strategic area, especially for developing irrigated rice fields in the irrigation area. In scoring the land map unit (SPT) following the technical guidelines issued by BBSDLP in 2016. More details can be seen in the following table.

Table 4. Table of Soil Mapping Units (SPT) in Gumbasa Irrigation Area

\begin{tabular}{|lllll|}
\hline No. & SPT & \multicolumn{1}{c}{ Land unit } & \multicolumn{1}{c|}{ Soil texture } & Area (ha) \\
\hline $\mathbf{1}$ & 1 & Aluvial Ustik dan Kambisol Eutrik & Medium texture & $1,20.92$ \\
$\mathbf{2}$ & 10 & Gleisol Fluvik dan Kambisol Ustik & Smooth texture & $2,150.49$ \\
$\mathbf{3}$ & 11 & Aluvial Ustik & Medium texture & 388.18 \\
$\mathbf{4}$ & 13 & Kambisol Eutrik dan Kambisol Gleik & Smooth texture & $1,150.71$ \\
$\mathbf{5}$ & 14 & Gleisol Eutrik, Gleisol Fluvik, dan Molisol Gleik & Smooth texture & 374.28 \\
$\mathbf{6}$ & 15 & Kambisol Eutrik dan Kambisol Gleik & Slightly smooth texture & 130.86 \\
$\mathbf{7}$ & 2 & Kambisol Eutrik dan Aluvial Eutrik & Medium texture & 319.66 \\
$\mathbf{8}$ & 24 & Kambisol Ustik dan Molisol Ustik & Medium texture & 56.78 \\
$\mathbf{9}$ & 4 & Gleisol Fluvik & Smooth texture & 957.48 \\
$\mathbf{1 0}$ & 40 & Kambisol Distrik dan Podsolik Haplik & Smooth texture & 20.57 \\
$\mathbf{1 1}$ & 5 & Gleisol Fluvik dan Aluvial Gleik & Smooth texture & $4,515.68$ \\
$\mathbf{1 2}$ & $\mathbf{5 5 5 5}$ & Settlement $(X 2)$ & Rough & $1,094.51$ \\
$\mathbf{1 3}$ & 6 & Kambisol Eutrik dan Gleisol Fluvik & Slightly smooth texture & $1,861.76$ \\
$\mathbf{1 4}$ & 9999 & Body of Water $(X 3)$ & Rough & 737.12 \\
\hline Total & & & 15,464 \\
\hline
\end{tabular}

Source: GIS analysis based on [16].

\section{Result And Discussion of land suitability assessment}

\subsection{Overlay land suitability parameters}

The following process in analyzing land suitability with a geographic information system (GIS) after assessing the suitability class of each parameter is the process of overlaying or overlapping between parameters. This process is carried out to combine all the information from the parameters used in the suitability analysis. In this exercise, the overlay process used is 'union'. In simple terms, the union process can be illustrated as follows:

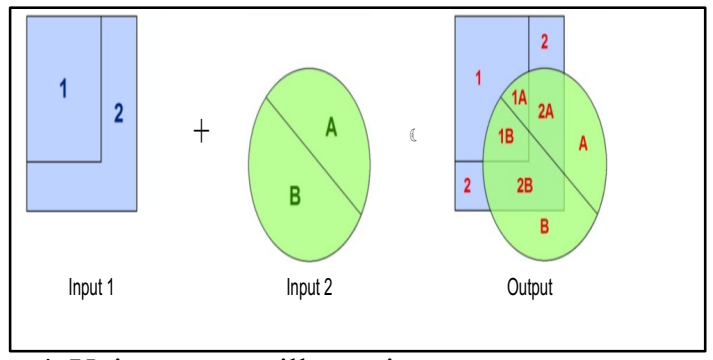

Fig. 4. Union process illustration.
In the union process, all data attributes from both inputs will be displayed on the output, both overlapping or not. As illustrated above, the following is an example of an overlayed data attribute with union:

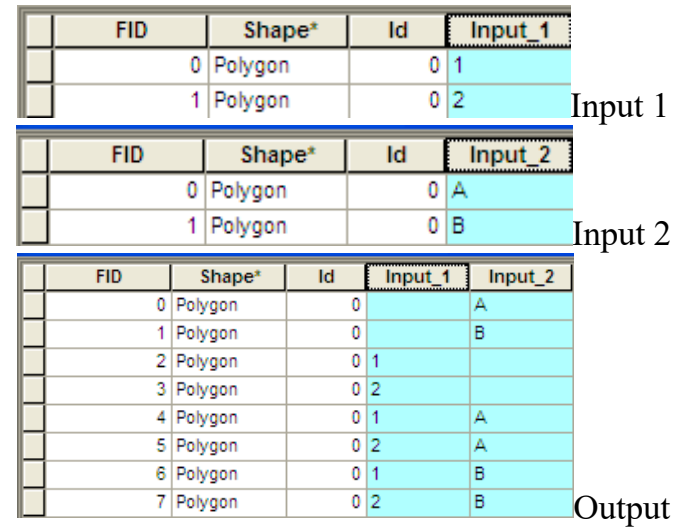

Fig. 5. Illustration of the data attribute of the union process.

\subsection{Reclass land suitability data overlay results}

After going through the overlay process, the next stage of land suitability analysis with a geographic information system (GIS) is reclassifying the suitability class of the overlay result. The determination of the new suitability class from the two old suitability classes is based on conformity. The S1 suitability class is only formed by the $\mathrm{S} 1$ and $\mathrm{S} 1$ classes. If there are two different land suitability classes, the new land suitability class is higher. This will affect the land suitability class because the suitability class will affect its use in the existing land use conditions. The following is a matrix of determining the new suitability class from two different suitability classes[16]:

Table 5. Table of slope data for Gumbasa Irrigation Area.

\begin{tabular}{|c|c|c|c|c|}
\hline Class Suitability & $S 1$ & $S 2$ & $S 3$ & $N$ \\
\hline$S 1$ & $S 1 * 1$ & $S 2 * 2$ & $S 3 * 3$ & $N^{* 4}$ \\
\hline$S 2$ & $S 2 * 2$ & $S 2 * 2$ & $S 3 * 3$ & $N^{* 4}$ \\
\hline$S 3$ & $S 3 * 3$ & $S 3 * 3$ & $S 3 * 3$ & $N^{* 4}$ \\
\hline$N$ & $N^{*} 4$ & $N^{* 4}$ & $N^{* 4}$ & $N^{* 4}$ \\
\hline
\end{tabular}

Source : [16]

\subsection{Soil Map Analysis Gumbasa Irrigation Area}

From the map, it can be seen that most of the cambisolustik and district cambisol soils are located in the eastern area of the irrigation location, where this area is adjacent to the main channel of DI Gumbasa. A higher slope than other areas also characteristic this area.

The dominance of cambisol material at this location is probably due to sand boiling during the earthquake in September 2018. Sand boiling occurs when sand and gravel material rises to the surface due to increased soil pore water pressure triggered by earthquake forces.

The type of material underneath on the east side is dominated by uitric cambisol and uitric gleisol, where this area is very dominant in the northern location of the test area, which includes the Maranata, Jono Oge and Petobo areas. In contrast, fluvic gleisol layers are 
primarily found in the Biromaru and Dolo areas, and a small part is in DI Gumbasa. For ustic alluvial soil texture, the dominant distribution is in the area along with the test site, located in the western region, which is close to the Palu river channel in Figure 6

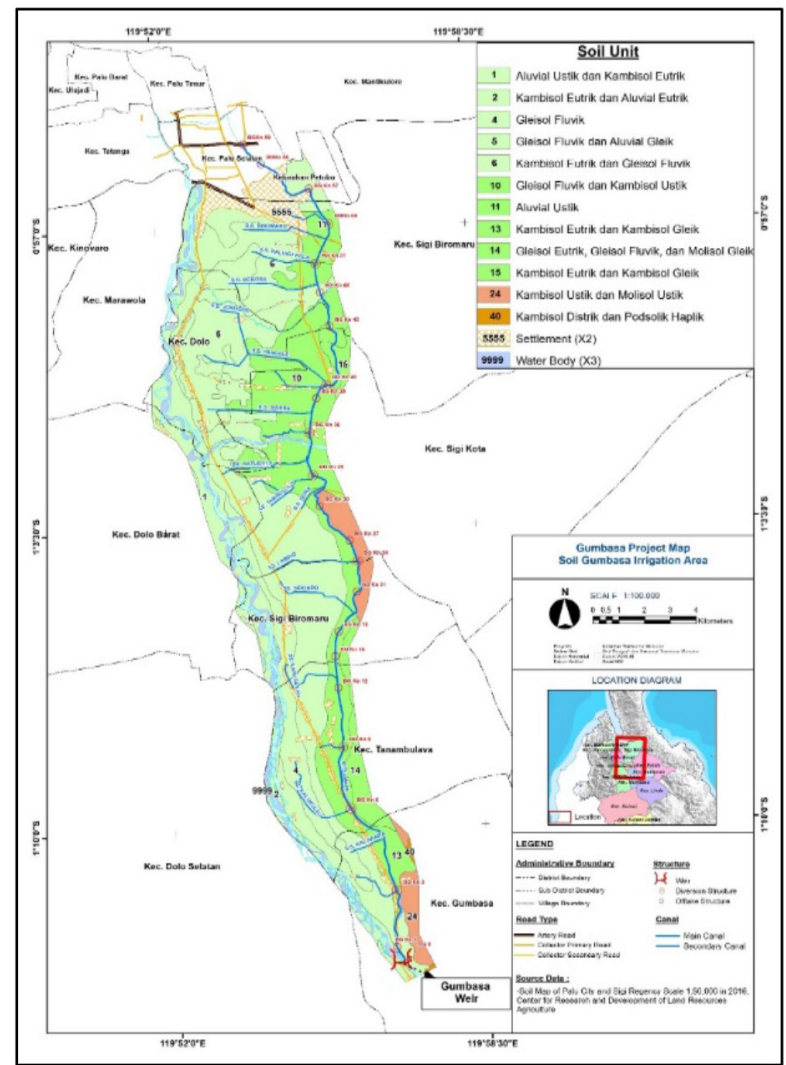

Fig. 6. Slope map of Gumbasa Irrigation Project.

\subsection{Slope data}

In classifying slopes for agricultural development, strategic areas are divided into four classes of slopes. It serves as a parameter in measuring the level of land suitability of the Gumbasa irrigation area as a boundary area. This is related to the development of strategic agriculture to find places suitable for use in irrigated rice fields. For more details, see the following table

Table 6. Slopes Classifying of Gumbasa Irrigation Area.

\begin{tabular}{|c|c|c|c|}
\hline No & Slope (\%) & $\begin{array}{l}\text { Area } \\
\text { (ha) }\end{array}$ & Category \\
\hline 1 & $<3 \%$ & $12,947.82$ & Highly suitable \\
\hline 2 & $3-5 \%$ & $2,240.94$ & Moderately suitable \\
\hline 3 & $5-8 \%$ & 202.09 & Marginally suitable \\
\hline 4 & $>8 \%$ & 73,15 & Not suitable \\
\hline \multicolumn{2}{|c|}{ Total } & 15,464 & \\
\hline
\end{tabular}

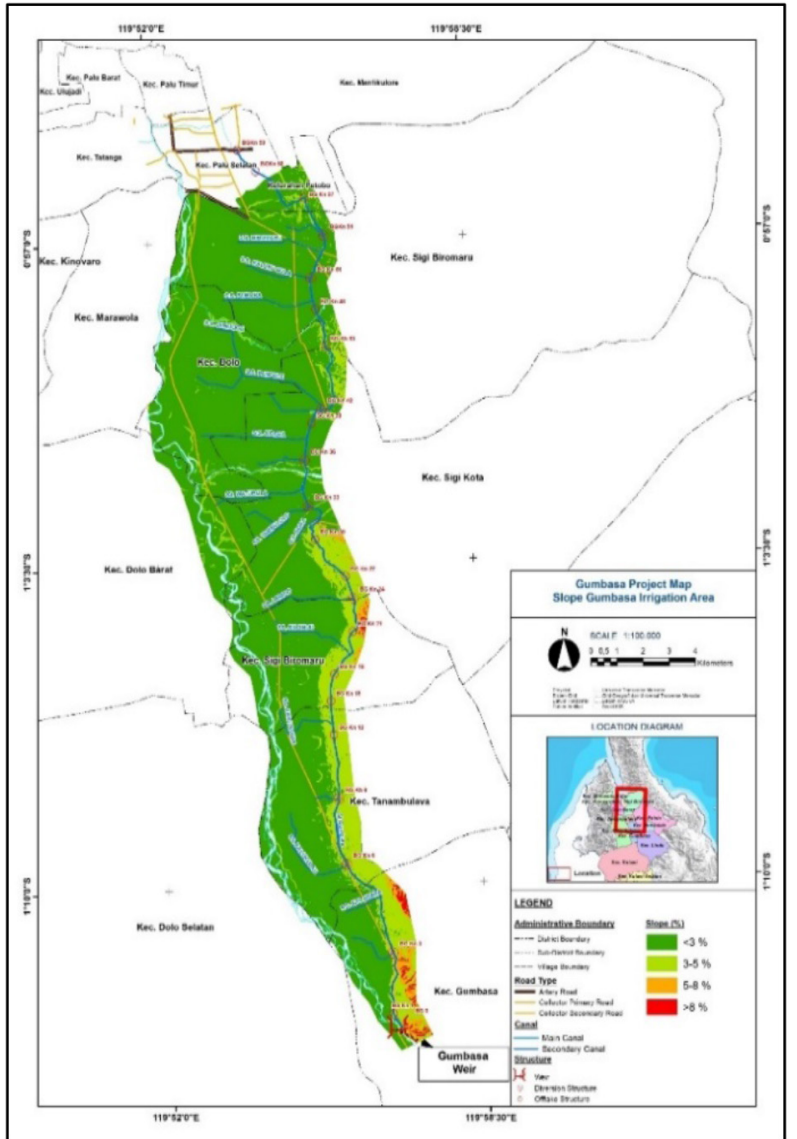

Fig.7. Slope map of Gumbasa Irrigation Project.

\subsection{Land use data}

The land use update of the Gumbasa Irrigation project is based on manual on-screen digitisation using Sentinel multi-temporal satellite imagery from 2016-2020 with a resolution of $10 \mathrm{~m}$. Digitisation activities for updating land use are based on different images using satellite data from various years. The original data on the land use of Gumbasa refers to the Sigi District Spatial Plan (RTRW) for 2020-2040 and the RTRW of Palu City in 2018-2038, as for the update of land use with highresolution orthophoto images that BIG issued in 2018 with a resolution of $1 \mathrm{~m}$ with ten land use classes, namely forests, transportation areas, grasslands, settlements, plantations, rice fields, shrubs, rivers, vacant land and fields/fields.

\subsection{The results of land use}

The change analysis is carried out by comparing the service from 2016 to 2020. By using the overlay technique, land-use change in Gumbasa is presented in the following table. 
Tabel 7. Land change 2016-2020 in Gumbasa irrigation.

\begin{tabular}{|c|c|c|c|c|c|c|}
\hline No. & Land use & 2016 & 2017 & 2018 & 2019 & 2020 \\
\hline 1 & Forest & 148 & 148 & 148 & 148 & 148 \\
\hline 2 & Transportation area & 11 & 11 & 11 & 11 & 11 \\
\hline 3 & Grassland & 0,49 & 0,49 & 0,49 & & \\
\hline${ }_{5}^{4}$ & Settlementractwities place & $\begin{array}{r}1,260 \\
2560\end{array}$ & $\begin{array}{l}1,423 \\
2649\end{array}$ & $\begin{array}{l}1,239 \\
2550\end{array}$ & 1,271 & $1,343^{2}-10$ \\
\hline 5 & Plantation/tree crap & 2,560 & $2,6,49$ & 2,550 & 2,538 & 2,650 \\
\hline 6 & Paddy fields & 6,794 & 7,079 & 6,575 & 6,418 & 6,585 \\
\hline & Shrubs/bushes & 819 & 916 & 845 & 873 & 1,265 \\
\hline $\mathbf{s}$ & River & 455 & 447 & 407 & 427 & 418 \\
\hline \multirow{3}{*}{10} & Bare land & & 149 & & 294 & 287 \\
\hline & Dry land agricult ure & 1,365 & 624 & 1,612 & 1,465 & 737 \\
\hline & & 15,464 & 15,464 & 15,464 & 15,464 & 15,464 \\
\hline
\end{tabular}

The analysis results show that changes in land use indicate a decrease in land use for agricultural cultivation areas, including rice fields, plantations and dry fields/fields. In contrast, the share of abandoned land in the form of shrubs and vacant land has increased after the natural disaster that occurred on 28 September 2018. The conversion of agricultural fields into residential areas in the Gumbasa irrigation area is a significant issue for irrigated agriculture, especially from 2016-2017. This trend decreased significantly due to liquefaction in 2018. Similarly, for almost all land use trends related to agricultural and non-agricultural land use, the natural disasters in 2018 had a major influence.

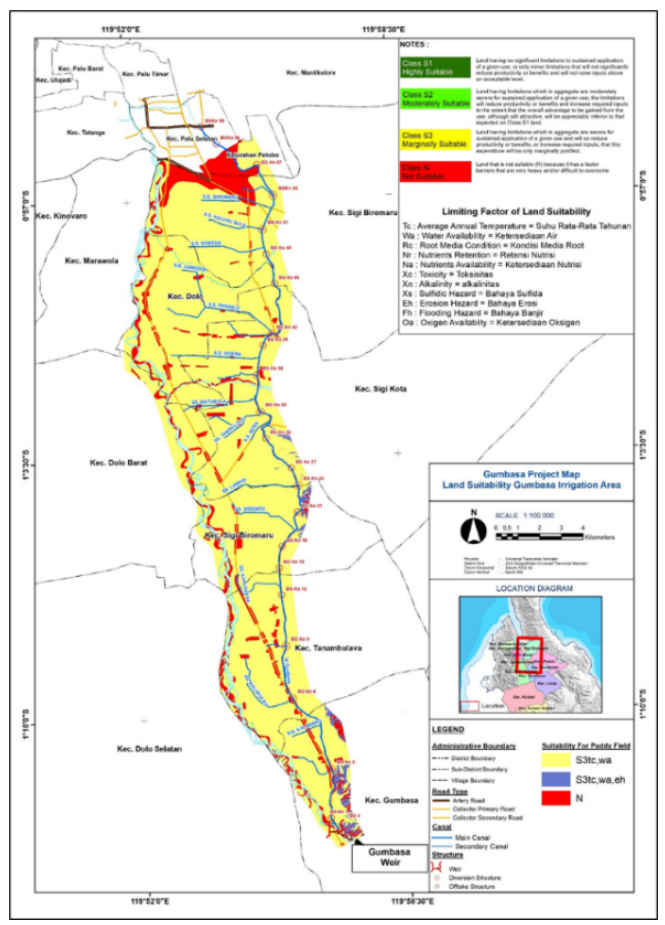

Fig. 8. Map of Land Suitability Gumbasa Irrigation Area.

The land suitability class criteria found in the Gumbasa irrigation area and the limiting factors that affect land suitability can be seen in the following table.

Table 8. Land suitability assessment Gumbasa Irrigation Area.

\begin{tabular}{|l|l|c|}
\hline No & \multicolumn{1}{|c|}{$\begin{array}{c}\text { Land Suitability assessment } \\
\text { class }\end{array}$} & $\begin{array}{c}\text { Area } \\
\text { (ha) }\end{array}$ \\
\hline 1 & S3tc, wa & $1,902.32$ \\
\hline 2 & S3tc, wa, eh & $13,364.47$ \\
\hline 3 & N & $1,902.32$ \\
\hline Total & 15,464 \\
\hline
\end{tabular}

Source: GIS analysis 2021

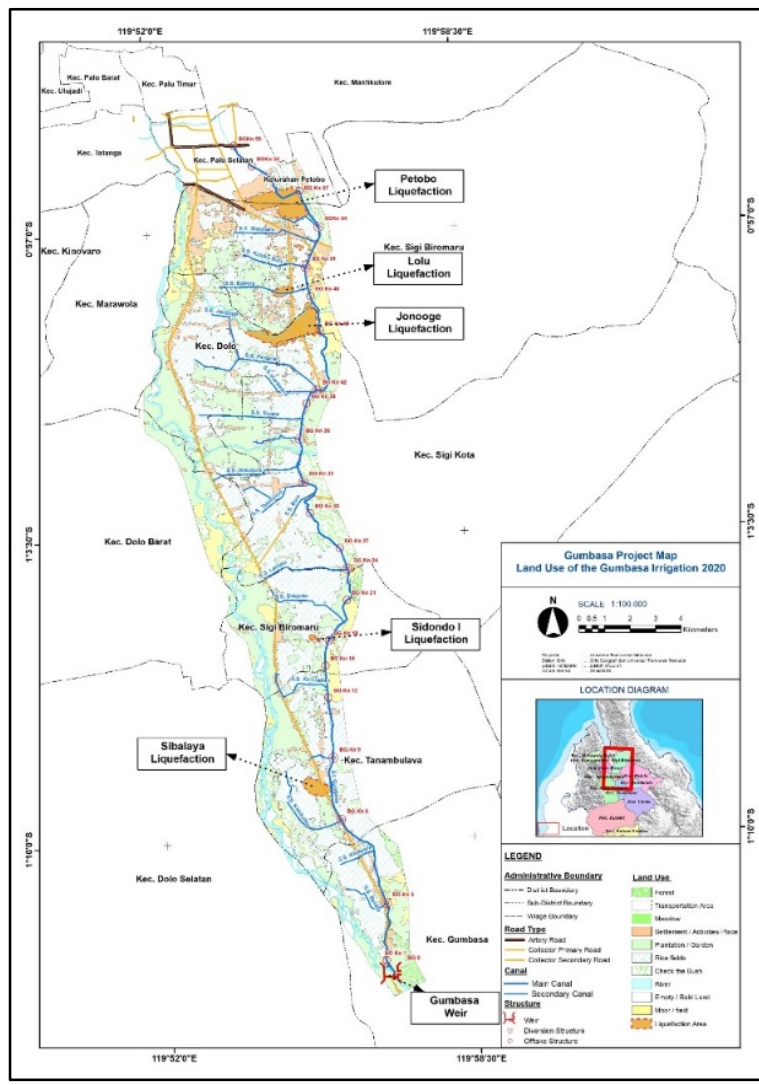

Fig. 9. Map of Land Use 2020 of Gumbasa Irrigation Area.

From the map, it can be seen that changes in agricultural land use caused by flow liquefaction in 3 main areas, namely Sibalaya, Jono Oge and Petobo are main reason that cause the changes in the area of paddy fields in the Gumbasa irrigation area. The second factor is a large number of shifts of agricultural land into residential land, especially the area Petobo in Palu City and the Biromaru and Dolo areas in Sigi Regency, especially those bordering Palu City.

\section{Concluding remarks}

The following are the conclusions of the Gumbasa Land Use and Land Suitability research:

1. The map projection used in the Gumbasa project follows the Indonesian National Standard (SNI) for Specifications for Presentation of topographic maps or base maps at a scale of $1: 25,000$ and for 1:1:50,000 (SNI 6502.2:2010 and SNI 6502.3:2010), which officially uses a map projection system UTM. Gumbasa is located in the UTM 50S zone; topographic/slope data is based on $1 \mathrm{~m}$ resolution of LiDAR BIG (National Geospatial Information Agency) data captured in 2018. At the same time, thematic data is classified based on project clusters in relation to Project supporting data analysis.

2. The result of the land suitability assessment map is a map of the calculation results based on the technical document Guidelines for Land Suitability Assessment for Strategic Agricultural Commodities at the Semi-Detailed Level 1:50,000 Scale issued by the Center for Agricultural Land Resources in 2016 related to the development of irrigated paddy 
3. Based on the results of the overlay (overlapping) assessment of land use and land suitability in the Gumbasa irrigation area, there are several inhibiting factors, namely the lack of water availability based on rainfall data for the last 15 years, it is known that the number of months $>200 \mathrm{~mm} / \mathrm{month}$ there are only two months in a year. The lack of wet months will affect the temperature of the related data. The Land Use and Land Suitability assessment results are included in the S3 category (marginally appropriate) for class/category classification.

4. Flow liquefaction triggered by the 2018 earthquake in 3 main areas, namely Sibalaya, Jono Oge and Petobo, causes the changes in the area of paddy fields in the Gumbasa irrigation area.

\section{References}

1. H. B. Mason, "Geotechnical Reconnaissance: The 28 September 2018 M7.5 Palu-Donggala, Indonesia Earthquake," no. September 2018, pp. 1-86, 2019, doi: 10.18118/G63376.

2. D. H. Natawidjaja et al., "The 2018 Mw7.5 Palu 'supershear' earthquake ruptures geological fault's multisegment separated by large bends: Results from integrating field measurements, LiDAR, swath bathymetry and seismic-reflection data," Geophys. J. Int., vol. 224, no. 2, pp. 985-1002, 2021, doi: $10.1093 /$ gji/ggaa498.

3. B. Mason, D. Hutabarat, and W. Prakoso, "Geotechnical Reconnaissance: The 28 September 2018 M7.5 Palu-Donggala, Indonesia Earthquake PacTrans-SSI Bridge Project View project AcehPidie Mw 6.5 Earthquake Aftershock 2016 Monitoring View project," Rep. Geotech. Extrem. Events Reconnaissance, Geotech. Extrem. Events Reconnaiss. Assoc., no. April, pp. 1-86, 2019, [Online].

Available: https://www.researchgate.net/publication/332221 717.

4. "BRIEF EXPLANATION PALU-KORO FAULT Summarized from Palu Earthquake Study by PUSGEN, 2018,” 2018.

5. Kementerian PPN/ Bappenas, "Rancangan Rencana Induk Pemulihan dan Pembangunan Wilayah Pasca Bencana di Provinsi Sulawesi Tengah," p. 74, 2018.

6. S. Nurdin et al., "Proceeding 23rd Annual National Conference on Geotechnical Engineering," no. November 2019.

7. D. Rohit, H. Hazarika, T. Maeda, W. O. Sumartini, and T. Kokusho, "Forensic Investigation of Flowslides Triggered by the 2018 Sulawesi Earthquake."

8. M. Okamura, K. Ono, A. Arsyad, U. S. Minaka, and S. Nurdin, "Large-scale flowslide in Sibalaya caused by the 2018 Sulawesi earthquake," Soils Found., 2020, doi: 10.1016/j.sandf.2020.03.016.

9. H. Hazarika et al., "Large distance flow-slide at Jono-Oge due to the 2018 Sulawesi Earthquake, Indonesia," Soils Found., vol. 61, no. 1, pp. 239255, 2021, doi: 10.1016/j.sandf.2020.10.007.

10. H. B. Mason et al., "East Palu Valley flowslides induced by the 2018 MW 7.5 Palu-Donggala earthquake," Geomorphology, vol. 373, 2021, doi: 1016/j.geomorph.2020.107482.

11. D. Rohit, H. Hazarika, T. Kokusho, S. Nurdin, and T. Maeda, "Forensic Investigation of Flow-slides Triggered by the 2018 Sulawesi Earthquake," 2018.

12. B. B. P. dan P. S. L. Pertanian, "Bbsdlp 2015," J. Chem. Inf. Model., vol. 53, no. 9, pp. 1689-1699, 2013.

13. J. Liu, "A GIS-based tool for modelling large-scale crop-water relations," Environ. Model. Softw., vol. 24, no. 3, pp. 411-422, 2009, doi: 10.1016/j.envsoft.2008.08.004.

14. A. AL-Taani, Y. Al-husban, and I. Farhan, "Land suitability evaluation for agricultural use using GIS and remote sensing techniques: The case study of Ma'an Governorate, Jordan," Egypt. J. Remote Sens. Sp. Sci., vol. 24, no. 1, pp. 109-117, 2021, doi: 10.1016/j.ejrs.2020.01.001.

15. R. Taghizadeh-Mehrjardi, K. Nabiollahi, L. Rasoli, R. Kerry, and T. Scholten, "Land suitability assessment and agricultural production sustainability using machine learning models," Agronomy, vol. 10, no. 4, pp. 1-20, 2020, doi: 10.3390/agronomy 10040573 .

16. L. Tahunan, "Bbsdlp 2016," 2017. 